\title{
E- Customer Care Service System for Benin Electricity Distribution Company
}

\author{
Olutayo Boyinbode \\ Department of Computer Science, \\ Federal University of Technology, Akure
}

\author{
Olufemi Akinyede \\ Department of Computer Science, \\ Federal University of Technology, Akure
}

\begin{abstract}
Good customer service is very important for any business to grow. Benin Electricity Distribution Company (BEDC),Akurebusiness district is responsible for distribution of electricity for people of Akure in Ondo State, Nigeria. Face to face customer contact is time consuming, since the consumershave to be physically present for both parties to meet before solution can be proffered. Telephone communication with BEDC enables the customers to call and make enquiriesand receive responses about information or services required. Consumers need strong communication skills in telephone communication which may be lacking in some cases; customers may need to go through several people before the ideal person who can help him is eventually reached. The BEDC existing customer service system is saddled with limitations such as poor customer services and relations, high response time. The need to improve on the weakness of the traditional customer services system led to the development of this e-customer service system. This paper aims to eliminate these weaknesses by automating the process through an e-Customer Care Service System by which customer makes an enquiries and complaints on the services delivered by the company.
\end{abstract}

\section{General Terms}

E-Customer Care System, Customer Support System.

\section{Keywords}

BEDC, Customer Care, E-customer care, Communications, Transactions

\section{INTRODUCTION}

All around the world, for effective business transaction between a business organization and the clients (the customers), there must be an effective means of communication between the organization and the customers $[4,5,6]$. Some business transactions persist for a long period of time as far as the consumer is still using the products and services offered by the organization. For example, in the telecommunication industry, when someone purchases a SIM card of a particular service provider and register it, then the business transaction between the subscriber and the service provider persist as long as the subscriber is still using the line. This transaction includes buying and loading of airtime for making calls, subscribing for data, applying for caller tune and the likes. When the subscriber has problem with the service provider in terms of service delivery, then there must be a means through which the subscriber can make complains about the problem. This is always done through the customer care of the service provider.

Benin Electricity Distribution Company (BEDC) Akure business district is responsible for caring for all the customers of BEDC in Akure, which is the capital of Ondo State in Nigeria. But it is quite unfortunate that the district which is the most important district in Ondo State does not have an effective customer care service system. This has led to poor communication between the district and the BEDC customers allocated to the district; thereby leading to poor transactions between the two parties and has created a level of inconvenience to the consumers and the district itself. For instance, when consumers have problems with bills, when their electric meter is malfunctioning or faulty, when there are problems with electric transmission cables or even when the transformer (s) of Particular Street (s) is faulty, the consumers involved in this problem have to inform the BEDC officials in their district. In Akure business district, the customer (s) involved in this problem has to write a letter directed to the BEDC district, take the letter in person to the customer care unit of the district. This may takes weeks before this letter get to the appropriate unit and before the problem is resolved. Also if the district wants to get to their customers or group of customers on issues that affect both parties, it is quitedifficult. In pursuit of finding solutions to the problems being faced by the subscribers of BEDC inAkure business district has motivated this work. The specific objectives to this work are to develop an e- customer care service system for BEDC. BEDCAkure business district lack an effective and efficient customer care service, which has led to poor flow of important information between the BEDC and the customers. .As a result of this, it is often difficult for consumers to lodge complaints make a request or an enquiry based on the issues they are ignorant of. For instant, if a consumer has problems with his/her bills or even meter, he/she has to write to the district in care of their area and take the letter in person to the district through the customer care unit. With this process, it always takes time before the complaint, enquiry or request get to the appropriate department of the district where the problem can be solved.

i. Also the district most time find it difficult to communicate with the customers either individual customer or groups of customers. This is as a result of when means of communication has failed; there is no means of getting to the customer(s).

ii. Even if there is available time for BEDC staff to attend to their customer, queuing system are very slow, leading to disrespect of human factor.

All these problems have led to poor delivery of service to the general public which has made the customers to lack confidence in the organization. For effective delivery of service to the general public, this problem of information flow between the two parties must be solved through an electronic customer care service $[7,8]$. 


\section{BEDC AKURE BUSINESS DISTRICT 2.1 Current Customer Service System in BEDC Akure Business District}

BEDC Akure Business District is one of the BEDC districts in Ondo State that is responsible for the distribution of electricity generated from the source (power station) to the consumers in Akure (capital of Ondo State). The existing customer care system in this district is by customer help desk. In this system, if a customer has any problem that needs to be resolved, they either call the customer help desk or write a letter about their problem and take it in person to the customer care unit of the district.

The first method which is by calling the customer help desk is not effective and convenient to the customers due to the following reasons:

i. Calling the customer help desk is not free since the normal call rate will be charged and this something prevent most customer from using this method to reach the customer care unit of the district

ii. This method of calling the customer help desk is not always available. For instance, the customer care unit closes by $4.00 \mathrm{pm}$ which is the official closing hour for the district. Also the customer care unit is not available during the weekends; there is no way where the customers can log complaints, requests and enquiries.

The second method of writing letters is not also effective as it does not comply with the instant feedback attribute of an electronic customer care service system. In this method, the letter can take like weeks or even months before it could get to the appropriate department of the district where the problem can be resolved. Disadvantages of the current customer care system service in the District:

i. Customers spend money in trying to get to the customer care unit of the district in terms of amount involved in calling the customer help desk

ii. The customer care unit is not always available since customers cannot log any complaint beyond 4.00 pm from Monday to Friday and during weekends. This contradicts the availability property of an effective customer care service system.

iii. The customer care system does not comply with the easily accessibility property of an effective customer care system since it is not automated.
Since the customer care service system in this district does not comply and effectively perform the function that a good customer care department of an organization should perform, hence there is need for an efficient customer care service system (e-customer Service).

\subsection{Description of Existing System}

The current customer care service system in Akure business district is by Customer Help Desk. In this system, any complaints or requests made by the customers will be recorded appropriately in the customer complaints logging form. This current method is far from effectiveness and some of its disadvantages had been discussed in Section 2.1. The description of the customer's complaint logging form is shown below in Table 1.

\subsection{Proposed Customer Care Service System for the District}

Due to all the flaws in the current customer care service system in the district and its inability to comply with an effective customer care that most effective organizations in developed countries use [ 1,2,3]. A web-based customer care service system is proposed. In this system, all customers will have user account with which they can $\log$ in all their complaints, requests and enquiries anytime and anywhere. Also instant feedback will be possible because the customer care agent will know how to reply to the customer's complaints either to the inbox of the customer in his/her account or directly to their mobile phone. This system will also provide easy accessibility because customers can access and use the system since it is online system. Advantages of the proposed system:

i. The system will provide instant feedback of any complaints, requests or complaints sent to the customer care unit.

ii. This system will provide easy access of the customers to the customer care system.

iii. This system will boost the confident of the customers on the BEDC since their problems will be taken care of as soon as possible.

iv. This system will rendered all the functionalities expected of an effective customer care service system

Table 1.Service Customer Relation Complaints Logging Form

\begin{tabular}{|c|c|c|c|c|c|c|c|c|}
\hline $\begin{array}{c}\text { S/N } \\
0\end{array}$ & $\begin{array}{c}\text { Date of } \\
\text { Complaint }\end{array}$ & $\begin{array}{c}\text { Time of } \\
\text { complaint }\end{array}$ & $\begin{array}{c}\text { Name of } \\
\text { complainant }\end{array}$ & $\begin{array}{c}\text { Nature of } \\
\text { problem }\end{array}$ & $\begin{array}{c}\text { Name \& } \\
\text { Address }\end{array}$ & $\begin{array}{c}\text { Phone } \\
\text { Number }\end{array}$ & Account ne & $\begin{array}{c}\text { Action } \\
\text { taken }\end{array}$ \\
\hline & & & & & & & \\
\hline & & & & & & & \\
\hline
\end{tabular}

\section{WEB BASED CUSTOMER CARE SERVICE SYSTEM}

A web-based secure customer care service system is developed using PHP and HTML. In this system customers will have individual user account with which they can use to login in to the system. This user account will allow the customers to be able to log all their complaints, requests and even make enquiries anytime anywhere. Also, the systems will have administrative account with which the customer care representative can reply the customer in form of message sent to the customer's account inbox. This system will also provide a medium where customers can search related problems and read about how they were solved. More also, the system will 
open a ticket in form of a logging form, where information can be obtained from the customers.

\subsection{System Implementation \\ 3.2 System Module}

The system consists of different modules such as home page, ticket submit page, view ticket page, ticket confirmation page, staff's login page, admin/ staff page, users page, categories page, knowledge base page, reports page, and profile page. The different modules are briefly explained below:

\section{Home page}

This is the page that will be displayed when the site is logged on to, it contains links to all other pages on the website(see figure 1). This is a page where customers can get linked to ticket page, view existing ticket page and also the staffs/admin of the BEDC can get linked to their login page.

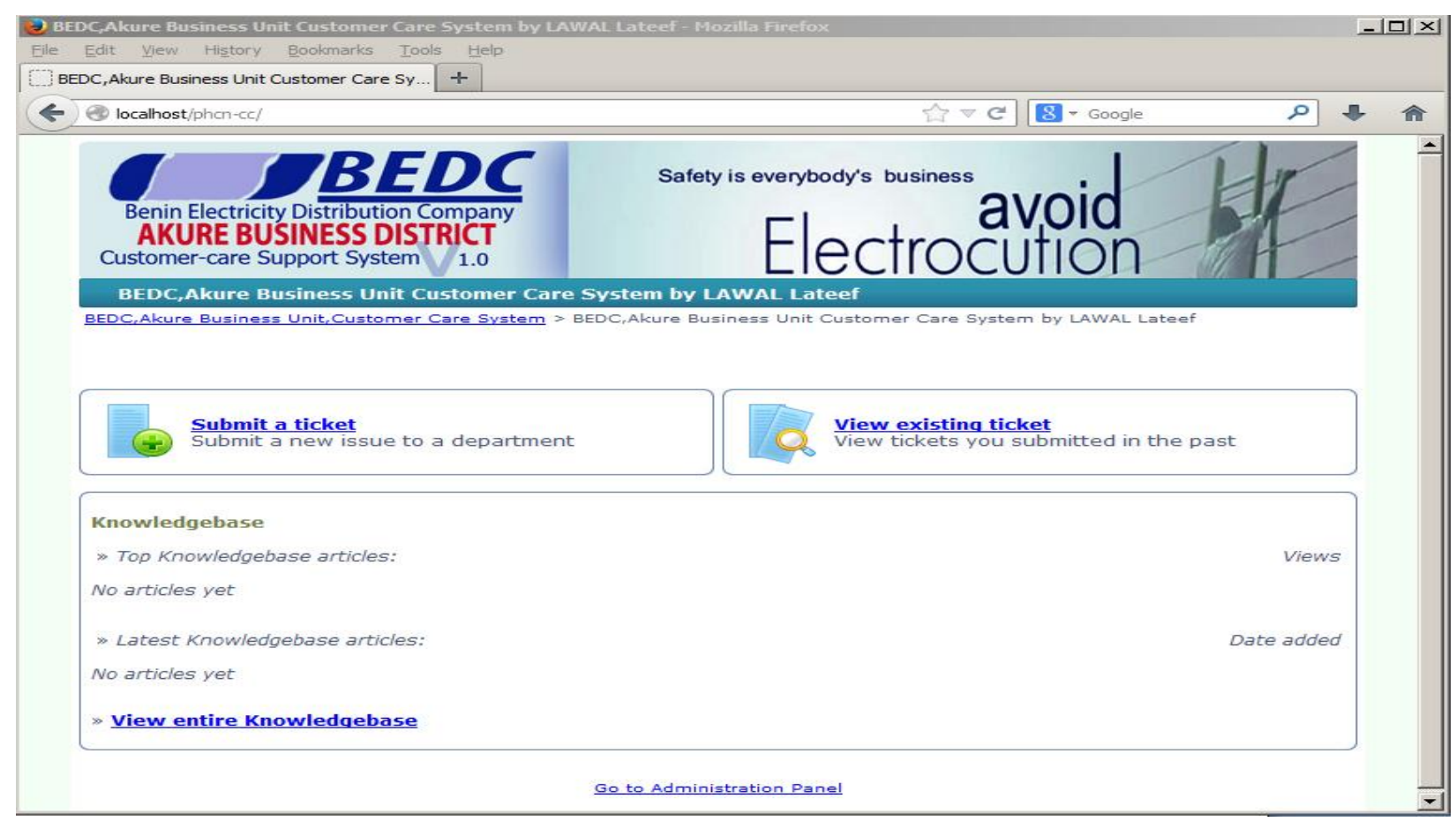

Fig1: Home page

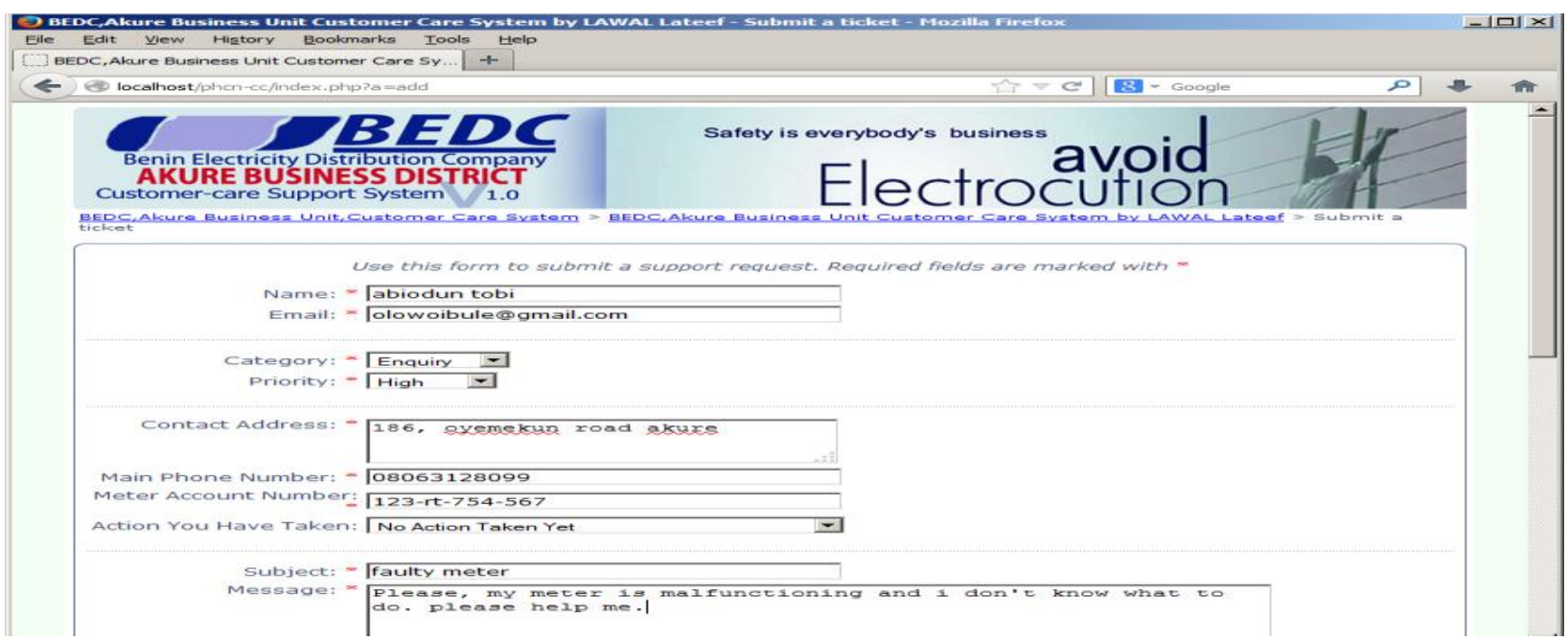

Fig2: Submit a Ticket Page

Submit a Ticket Page: This is a page where customer can submit a ticket. A ticket is like a form where the customers can enter their details including their messages (See figure 2).Ticket Submission Confirmation Page: This is the page that confirmed that your ticket has been successfully submitted. It contains a tracking id that enables the user to view the status of the submitted ticket (See figure 3). 


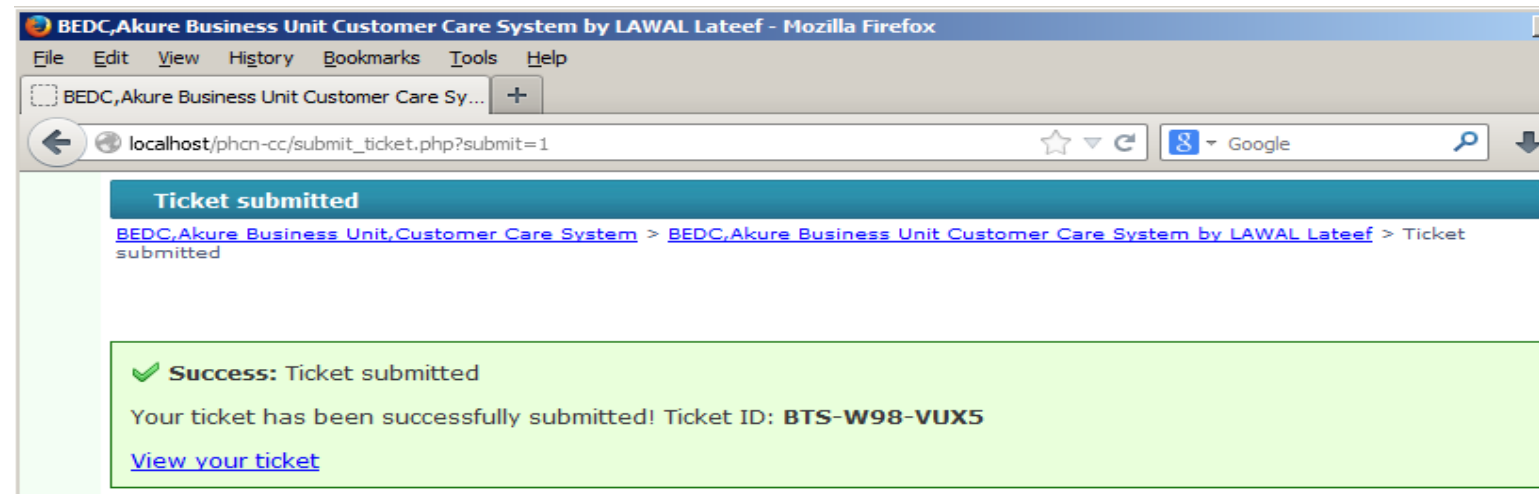

Fig 3: Ticket submission confirmation Page

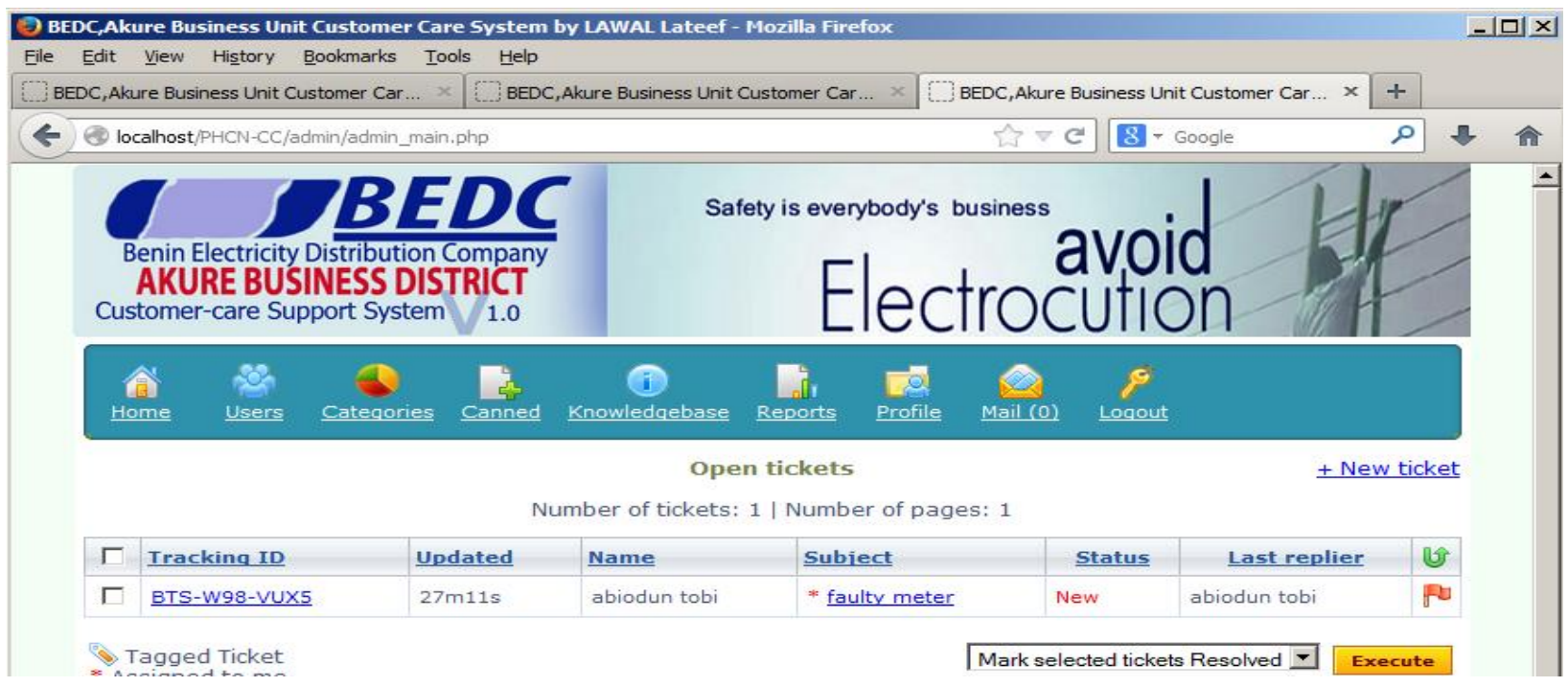

Fig 4: Administrator page showing sent ticket

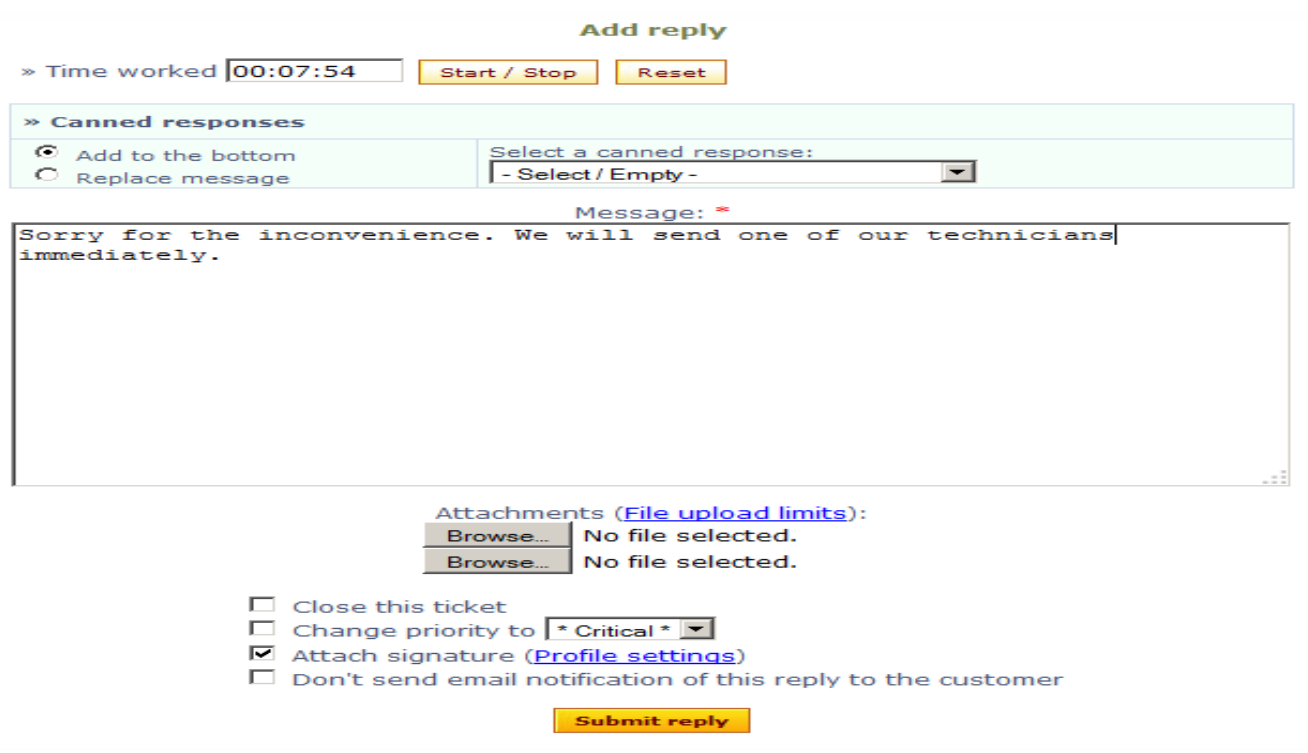

Fig 5:Administrator replying to ticket 
Figure 4 above shows the administrator page that contains new ticket to be treated and figure 5 the page showing where the administrators reply to ticket
This is a page that enables the user to view the status of their ticket by using the tracking id. After entering the tracking id and click on view ticket, it will display figure 6 and 7 as shown below:

\section{Viewing Existing Ticket Page}

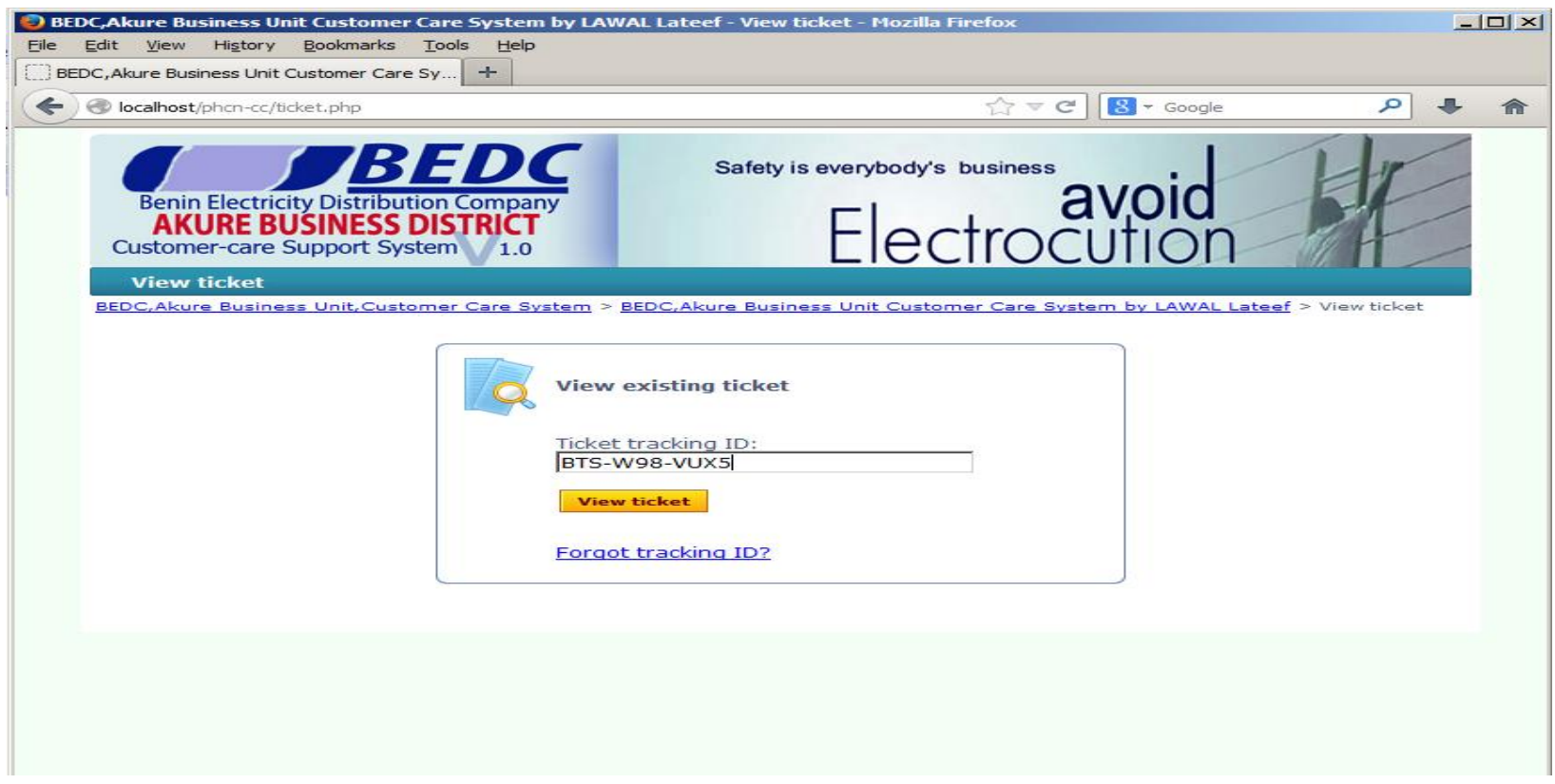

Fig 6: View Existing Ticket Page

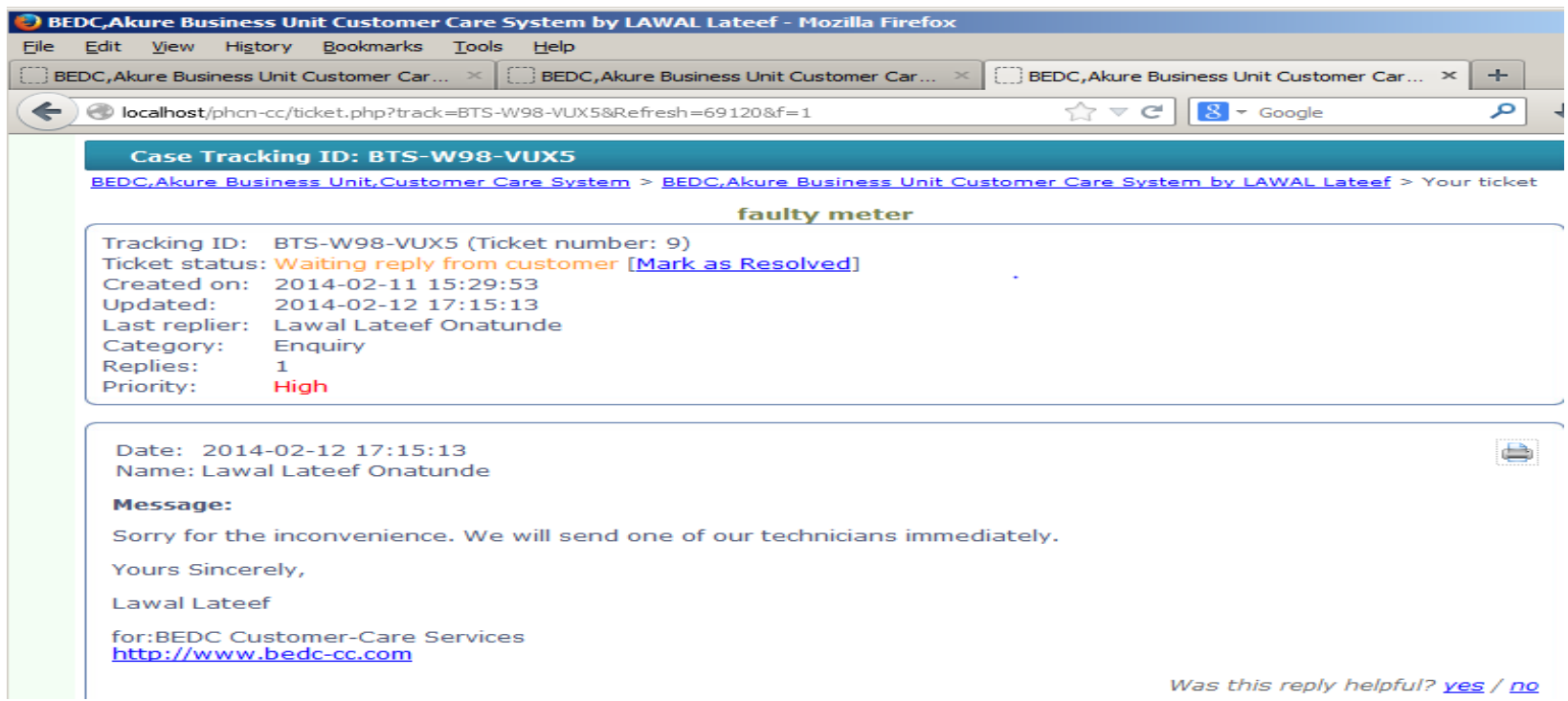

Fig 7: page showing the status of sent ticket

\section{CONCLUSION}

This paper describes and implements a web-based customer care service system for Benin Electricity Distribution Company Akure business district. The design and implementation of the project was successful. Staff of BEDC and their customers will benefit immensely from this system. The problems faced by customers when trying to get across to the customer care representative of the district will be a thing of the past. And also, this system will boost the confidence of the staff of BEDC and improve their productivity. This system will also simulate a virtual environment with real time web presence for common problem solving technique with the help of knowledge-base article presented to the customer, for instance creating an article based on FAQ (Frequently Asked Questions).

\section{REFERENCES}

[1] Ankomah,R., and Naeem ,M. (2004). Customer Feedback Online Case studies of Swedish Manufacturing SMEs. Second edition, Wiley, New York.

[2] Customer service http://en.wikipedia.org/wiki/Customer_service, accessed on $24^{\text {th }}$ July, 2014

[3] Hallowell, R. (1996). "The Relationships of Customer Satisfaction, Customer Loyalty, and Profitability: An Empirical Study. InternationalJournal of Service Industry Management 7(4), 27-42

[4] Humphrey (2012). 10 Benefits of Good Customer Services,http://www.broadcastsystemsintegration.com/10 
11/10-benefits-of-good-customer-services/ accessed on $27^{\text {th }}$ July 2014

[5] Margaret Rouse (2007). Customer Service and Support, http://searchcrm.techtarget.com/definition/customerservice-and-support accessed on $28^{\text {th }}$ July 2014

[6] Susan A. Friedmann (2013). The Ten Commandments of Great Customer Service, http://www.about.com/TheTen-Commandments-of-Great-Customer-Service.htm
[7] Turban, E. (2002). Electronic Commerce: A Managerial Perspective. New York, Prentice Hall

[8] Wang I.M. And Shieh C.J. (2005). The relationship between service quality and customer satisfaction: the example of CJCU library, Journal of Information \& Optimization Sciences Vol. 27 (2006), No. 1, pp. 193209 